\title{
Abusive Swearing Variations In The Temanggung Javanese Dialect: Type and Social Reality
}

\author{
Ira Mayasari*), \\ Universitas Indraprasta PGRI \\ Ahmad Muzaki \\ Universitas Indraprasta PGRI \\ *) Jalan Nangka, Gg. Batas Barat II No. 24 RT 12/04, Kel. Baru, Jakarta Timur, Indonesia; \\ e-mail: bunazmina@gmail.com
}

\begin{abstract}
This study aims to describe the types of Temanggung dialect Javanese language curses, as well as their functions in social life. The analysis in this study uses sociolinguistic studies. The method of data collection is carried out by means of competent listening because it is in the form of observation and observation, and is assisted with oral and written data. The results of this study are found in several types of swear, including swear based on limb 10, swear animal name 4, swear profession name negative 1 , part 1 tree, no swear referent 32 , intelligence 2 condition, and mental health 4 . The most common types of swear are swear no referents because sometimes swear forms do not have an original word and are formed conventionally in each region. Thus, swearing in each region certainly varies according to the agreement of the area. Based on its function, in this study found 7 functions, namely the means to express anger, resentment, disappointment, wonder, regret, insult and familiarity.
\end{abstract}

Keywords: Abusive Swearing, Temanggung Javanese Dialect.

Article History: Received: 26/05/2019; Revised: 22/06/2019; Accepted: 27/07/2019; Published: 31/07/2019. How to Cite (MLA $7^{\text {th }}$ ): Muzaki, Ahmad, Ira Mayasari. “Abusive Swearing Variations in the Temanggung Javanese Dialect: Type and Social Reality." Hortatori Jurnal Pendidikan Bahasa dan Sastra Indonesia 3.01 (2019): 64-72. Print/Online. Copyrights Holder: Ahmad Muzaki, Ira Mayasari. First Publication: Hortatori Jurnal Pendidikan Bahasa dan Sastra Indonesia (2019).

This work is licensed under a Creative Commons Attribution-ShareAlike 4.0 International License.

\section{Pendahuluan}

Bahasa dan masyarakat bagaikan dua sisi mata uang. Bahasa ada karena masyarakat, masyarakatpun hidup dengan bahasa. Bahasa akan terus berkembang, sesuai dengan sifat bahasa yang dinamis. Perkembangan bahasa diimbangi dengan perkembangan masyarakat. Semakin kreatif penggunaan bahasa dalam masyarakat, maka semakin berkembang pula bahasa yang ada. Bahasa digunakan untuk berkomunikasi, diantaranya untuk mengungkapkan perasaan senang, sedih, marah/emosi, lucu, dan sebagainya, untuk mengungkapkan perasaan, tentunya menggunakan bahasa yang berbeda-beda. Ketika orang sedang bersedih, pasti akan berbeda dengan bahasa orang yang sedang merasa senang, takut, bahkan marah. Bahasa pada tiap masyarakat memiliki ciri khas yang berbeda-beda. Misalkan saja pada kata umpatan atau sering disebut sebagai makian. Umpatan pada tiap daerah pasti berbeda-beda karena umpatan bersifat konvensional atau berdasarkan kesepakatan bersama. Masyarakat A belum tentu mengerti arti umpatan pada masyarakat B. Begitu juga sebaliknya, masyarakat B belum tentu mengerti arti umpatan pada masyarakat A. Bahkan, terkadang umpatan tidak dipahami sebagai umpatan karena adanya perbedaan kesepakatan bahasa pada tiap daerah. Misalkan, pada saat orang Jawa mengatakan sikak, belum tentu orang Sunda mengetahui bahwa kata tersebut adalah bentuk umpatan. Pada penelitian ini, umpatan yang akan dikaji adalah umpatan bahasa Jawa, dialek Temanggung, khususnya kecamatan Candiroto. Kota Temanggung merupakan sebuah kabupaten yang terletak di Jawa Tengah. Kota ini terdiri dari beberapa kecamatan, namun, Kecamatan Candiroto dipilih sebagai objek untuk memeroleh data karena salah satu 
peneliti berasal dari kecamatan tersebut. Selain itu, ada keunikan beberapa umpatan yang berbeda dengan daerah lain, misalkan pada kata sikak, celeng, dan mbiying. Keunikan-keunikan pada tiap ucapan dalam umpatan tersebut membuat penulis tertarik untuk menganalisis bentuk, fungsi, dan penyebab orang bisa mengumpat.

Penelitian ini menggunakan teori sosiolimguistik. Menurut Wijana, (2010:7) sosiolinguistik merupakan cabang linguistik yang memandang atau menempatkan kedudukan bahasa dalam hubungannya dengan pemakai bahasa itu di dalam masyarakat. Umpatan merupakan salah satu bentuk bahasa yang diciptakan oleh masyarakat. Dengan demikian, bentuk umpatan pada tiap daerah memiliki kecenderungan yang berbeda-beda. Umpatan sama dengan makian, sedangkan makian sendiri berasal dari kata maki. Maki adalah mengeluarkan kata-kata atau (ucapan) keji (kotor, kasar, dan sebagainya) sebagai pelampiasan kemarahan atau rasa jengkel (KBBI, 2016: 863). Umpatan dibagi menjadi 10, yaitu: anggota tubuh, nama binatang, nama profesi bermakna negatif, nama bagian pohon, nama peralatan makanan, nama anggota keluarga, nama orang, umpatan tak ada referen, kondisi inteligensia, dan kesehatan mental Djatmika (2016: 25). Umpatan juga memiliki fungsi dalam kehidupan sosial. Fungsi-fungsi tersebut diantaranya, sarana untuk mengungkapkan rasa marah, kesal, kecewa, menyesal, heran, menghina orang lain, dan menggambarkan keakraban dalam sebuah hubungan Saptomo (dalam Yuliarini 2014: 40).

\section{Metode}

Penelitian ini menggunakan metode deskriptif kualitatif. Maksud penelitian kualitatif adalah untuk memahami fenomena tentang apa yang dialami oleh subjek penelitian, misalnya perilaku, persepsi dan lainlain. Laporan penelitian ini berupa kutipan-kutipan data untuk memberi gambaran penyajian laporan tersebut (Moleong, 2013:11). Metode ini digunakan untuk menggambarkan objek penelitian agar sesuai dengan data yang diperoleh. Metode yang dipakai untuk pengumpulan data adalah metode simak bebas libat cakap. Data diperoleh dari sumber lisan dan tulisan.

\section{Hasil dan Diskusi}

Tabel 1. Hasil data variasi umpatan bahasa Jawa dialek Temanggung

\begin{tabular}{|c|c|c|}
\hline No & Data & Arti \\
\hline 1 & Cocotmu & Ucapanmu \\
\hline 2 & Lambemu & Bibirmu/ucapan \\
\hline 3 & Ndasmu & Kepalamu \\
\hline 4 & Gundulmu & Kepalamu \\
\hline 5 & Sikak & Sialan \\
\hline 6 & Celeng & Menyamakan orang dengan hewan \\
\hline 7 & Bajingan & Kurangajar \\
\hline 8 & Ciblek & Sejenis burung (Wanita murahan) \\
\hline 9 & Silit & Lubang pantat \\
\hline 10 & Cangkeman & Berbicara terus \\
\hline 11 & Nyonyormu & Mulutmu \\
\hline 12 & Asu & Menyamakan orang dengan hewan \\
\hline 13 & Matamu & Matanya \\
\hline 14 & Goblok/goblokan & Bodoh \\
\hline 15 & Pekok & Kotoran \\
\hline 16 & Thelo & Sialan \\
\hline 17 & Sikem & Sialan \\
\hline 18 & Dengkulmu & Lututmu \\
\hline 19 & Celes & Sialan \\
\hline 20 & Asem & Sialan \\
\hline 21 & Nggatis & Cerewet \\
\hline 22 & Cawak & Nyablak \\
\hline 23 & Ndopok & Berbicara terus/berbohong \\
\hline
\end{tabular}




\begin{tabular}{lll}
24 & Metengsel & Sombong \\
25 & Ora Teyeng & Tidak bisa \\
26 & Anggak & Sombong \\
27 & Mbiying & Bandel \\
28 & Ndablek & Bandel \\
29 & Mbejujag & Bandel \\
30 & Modar & Mati/meninggal \\
31 & Sutik & Tidak mau \\
32 & Nggambleh & Suka nyiyir \\
33 & Ngglitis & Usil/hiperaktif \\
34 & Nggragas & Apa saja dimakan \\
35 & Kranjingan & Kurangajar \\
36 & Mangas & Makan apa saja dal;am jumlah banyak \\
37 & Nguntal & Makan \\
38 & Ompakan & Banyak gaya \\
39 & Semangkean & Tidak serius \\
40 & Tambeng & Bandel \\
41 & Umis & Cerewet \\
42 & Lamis & Cerewet/biang gosip \\
43 & Mbetu & Bandel \\
44 & Bombongan & Banyak gaya \\
45 & Cengengesan & Senyum-senyum/tidak serius \\
46 & Lambe turah & Biang gosip \\
47 & Mecicil & Bandel dan melotot (menantang) \\
48 & Jotek & Sangat tidak mau \\
49 & Jidor & Cuek/tidak peduli \\
50 & Kirik & Anak anjing \\
51 & Edan & \\
52 & Gendeng & \\
53 & Koplak & \\
54 & Kenthir & \\
\hline & & \\
\hline &
\end{tabular}

\section{Jenis-jenis Umpatan}

1. Anggota Tubuh

Umpatan berjenis anggota tubuh dalam penelitian ini ditemukan pada data cocotmu, lambemu, ndasmu, gundulmu, nyonyormu, matane, silit, cangkeman, dengkulmu, dan lambe turah. Cocotmu dan nyonyormu memiliki arti mulut dan berkaitan dengan ucapan tidak baik yang dikeluarkan dari mulut seseorang. Lambemu memiliki arti bibirmu, ndasmu dan gundulmu memiliki arti kepalamu. Matane memiliki arti matanya. Silit berarti lubang pantat, sedangkan cangkeman berasal dari kata cangkem 'mulut', jadi cangkeman berarti berbicara terus. Dengkulmu memiliki arti anggota tubuh yaitu lutut (lututmu), sedangkan lambe turah memiliki arti bibir sisa 'biang gosip'.

2. Nama Binatang

Umpatan berjenis nama binatang ditemukan pada kata celeng, asu, ciblek, dan kirik. Celeng memiliki arti sejenis hewan yaitu babi hutan, asu memiliki arti hewan anjing, ciblek merupakan sejenis burung yang memiliki arti perempuan murahan (wanita panggilan), sedangkan kirik memiliki arti anak anjing.

3. Nama Profesi Bermakna Negatif

Umpatan berjenis nama profesi bermakna negatif ditemukan pada kata bajingan. Bajingan berarti kurangajar.

4. Nama Bagian Pohon

Jenis umpatan yang merupakan nama pohon hanya ditemukan pada kata asem atau diartikan sebagai sialan.

5. Umpatan tak ada referen 
Umpatan tak ada referen ditemukan pada sikak, thelo, sikem, celes, nggatis, cawak, ndopok, metengsel, teyeng, mbiying, anggak, ndopok, ndablek, mbejujag, modar, sutik, nggambleh, ngglitis, nggragas, kranjingan, mangas, nguntal, ompakan, semangkean, tambeng, umis, lamis, mbetu, bombongan, cengengesan, mecicil, jotek, jidor.

6. Kondisi Inteligensia

Umpatan jenis inteligensia ditemukan pada kata goblok atau goblokan dan pekok yang memiliki arti bodoh.

7. Kesehatan Mental

Umpatan jenis kesehatan mental ditemukan pada data edan, gendeng, koplak, kenthir.

\section{Fungsi Umpatan}

1. Sarana untuk Mengungkapkan Rasa Marah

Pada dasarnya, ketika seseorang marah, mereka akan mengeluarkan ekspresi yang berbeda. Ekspresi tersebut diwujudkan dalam bentuk emosi, yang terkadang membuat seseorang berkata kasar, kotor, dan tidak soapan. Rasa marah muncul saat seseorang merasa diperlakukan tidak baik. Contoh umpatan yang digunakan untuk menunjukkan rasa marah, cocotmu, lambemu, ndasmu, dengkulmu, goblok, pekok (pethuk, )sikak, celeng, bajingan, cangkemam, nyonyormu, asu, kranjingan, dan kirik. Contoh tuturan:

(1) Cocotmu mbok datur. (omonganmu/ perkataanmu tolong diatur).

(2) Lambemu koyo ra dizakati. (bibirmu seperti tidak dizakati).

(3) Ndasmu! (Kepalamu)

(4) Dengkulmu, nek omong ra dipikir.

(Lututmu, kalau berbicara tidak dipikir.)

Kalimat semacam ini keluar saat seseorang marah dengan lawan tuturnya, sehingga perkataan atau omonganmu yang lebih halus diganti menjadi cocotmu dan lambemu. Ndasmu dan dengkulmu juga merupakan umpatan yang digunakan untuk mengungkapkan perasaan emosi. Ungkapan tersebut muncul karena penutur merasa marah, mungkin tersinggung, mungkin juga persasaannya tersakiti sehingga merasa emosi dengan lawan tutur.

(5) Woii... goblok!

(Woii... bodoh!)

(6) Pekok (pethuk) banget dadi uwong!

(bodoh sekali jadi orang!)

Kata goblok dan pekok merupakan umpatan sebagai bentuk ekspresi marah. Kata-kata tersebut sangat kasar dan tidak terpuji.

(7) Sikak de'e ke, wani po?

(Sialan kamu itu, berani apa?)

Kata sikak keluar pada saat seseorang merasa sangat marah dengan lawan tuturnya, sampai-sampai keluar umpatan, yaitu kata sikak 'sialan.'

(8) Celeng de'e ke cenan.

(Celeng kamu itu emang)

(9) Kowe ki pancen asu!

(Kamu itu memang anjing!)

(10) Pancen kirik!

(Emang anak anjing!) 
Pada tuturan tersebut, kata celeng memiliki arti seekor babi hutan. Tuturan semacam itu akan keluar jika seseorang benar-benar marah sehingga orang yang membuatnya marah disamakan dengan hewan, yaitu celeng. Pada tuturan kedua, kata asu juga memiliki arti seekor binatang, yaitu anjing. Karena begitu marah, orang disamakan dengan hewan anjing sebagai bentuk luapan emosi marah. Begitu juga dengan tuturan ketiga, orang disamakan dengan binatang, yaitu kirik 'anak anjing' .

(11) Dasar bajingan!!!

(Dasar kurangajar/penjahat!!!)

(12) Ooo... bocah kok kranjingan temen.

(Ooo... anak kok kurangajar sekali.)

Kata bajingan pada tuturan tersebut memiliki arti kurangajar atau diartikan sebagai seseorang yang berperilaku tidak terpuji, seperti penjahat. Seseorang dapat mengucapkan kata-kata itu karena orang tersebut berperilaku tidak sopan sehingga keluarlah rasa emosi. Kata kranjingan pada kalimat tersebut juga muncul pada saat orang merasa marah. Kranjingan berarti kurangajar.

(13) Eh, dadi uwong mbok ora cangkeman wae!

(eh, jadi orang jangan kebanyakan omong!)

(14) Nyonyormu mbok ngati-ati. (mulutmu hati-hati)

2. Sarana untuk Mengungkapkan Rasa Kesal,

Umpatan yang digunakan untuk menjunjukkan rasa kesal, matane, sikem, nggatis, cawak, metengsel, anggak, mbiying, ndablek, mbejujag modar, sutik, mangas, nggragas, ompakan, tambeng, lambe turah, mecicil, jotek, dan jidor.

(15) Matane, nek mlaku mbok ndelok-delok. (matanya, kalau jalan lihat-lihat.)

Matane pada data (11) berarti matanya.

Tuturan tersebut keluar karena seseorang merasa kesal. Saat naik motor, tertabrak dari belakang sehingga spontan mengeluarkan kata umpatan matane.

(16) Sikem ah, ra takon.

(sialan ah, tidak tanya)

(17) Thelo kowe ra omong. (Sialan kamu tidak bilang.)

Kata sikem dan thelo berarti sialan. Tuturan ini muncul saat seseorang merasa kecewa karena teman yang dikenalnya tidak menyapa.

(18) Nggatis wae cah ke.

(ngomong/berbicara terus anak ini)

(19) Bocah kok lamis banget.

(Anak kok pintar berbicara/memutarbalikkan fakta)

Kata nggatis dan lamis berarti seseorang yang suka berbicara terus, tetapi berkonotasi negatif. Berbicara dalam arti membicarakan orang lai ataupun mengeluh apa saja yang terjadi pada dirinya.

(20) Oalaaah... cah wedok kok cawak men.

(oalaaah... anak perempuan kok berbicaranyanya keras sekali/teriak-teriak.)

Kata cawak berarti berbicara keras dan suka teriak. Tuturan tersebut muncul saat seseorang merasa tidak nyaman karena ada seorang perempuan yang berbicaranya keras sekali. Meskipun dalam jarak yang dekat, suaranya tetap teriak-teriak. 
(21) Cah cilik kok metengsel temen.

(anak kecil kok banyak gaya.)

(22) Titeni wae, saiki anggak e pol

(Lihat saja, sekarang sombong sekali.).

Kata metengsel dan anggak memiliki arti yang hampir sama. Metengsel berarti banyak gaya, sedangkan anggak berarti sombong. Umpatan ini muncul pada saat seseorang merasa kesal dengan tingkah laku orang lain, yang dirasa tidak wajar.

(23) Bocah kok mbiying temen.

(Anak kok bandel sekali)

(24) Ooo..., dasar cah ndablek, awas mengko nek bali.

(Ooo..., dasar anak bandel, awas nanti kalau pulang.)

(25) Dadi bocah mbok ora mbejujag!

(Jadi anak itu jangan bandel.)

Kata mbiying, ndablek, mbejujag, ngeyel memiliki arti yang sama, yaitu bandel. Kata-kata tersebut diucapkan saat seseorang merasa kesal karena merasa nasihatnya tidak didengar. Sasaran pada ucapan ini biasanya anak kecil.

(26) Modar to, daikandani ngeyel.

(Mati/mampus kan, dinasehati tidak percaya.)

Kata modar berarti mati atau mampus. Kata ini diucapkan saat seseorang merasa kesal sehingga mengumpat dengan kata modar.

(27) Sutik/jotek temen ak ro cah kae.

(Benar-benar tidak mau ak sama anak itu.)

Kata sutik berarti benar-benar tidak mau. Kata tersebut muncul sebagai bentuk perasaan kesal dan tidak suka saat dijodohkan sehingga menjawab dengan kata sutik atau jotek.

(28) Anakke Yu Parmi ke pancen do mangas, lawuhe entek kabeh. (Anaknya Yu Parmi itu memang banyak makan, lauk habis semua.)

(29) Bocah kok nggragas temen, jambu mentah wae pangan. (anak kok apa-apa dimakan, jambu masih mentah dimakan.)

Kata mangas dan nggragas memiliki arti yang hampir sama. Mangas ditujukan untuk seseorang yang banyak makan, makan berlebihan, dan tidak aturan. Orang yang merasa kesal akan menyebutnya dengan kata mangas. Nggragas ditujukan untuk orang yang memakan apa saja, bahkan sesuatu yang seharusnya belum saatnya dimakan sudah dimakan.

(30) Ompakan temen to bocah kae, numpak honda ngebut-ngebut. (Banyak gaya sekali anak itu, naik moter sangat cepat.)

Ompakan memiliki arti banyak gaya. Tuturan tersebut ditujukan untuk seseorang yang banyak gaya karena naik motor kencang sekali.

(31) Mbok ra tambeng nek kandani ke. (Jangan bandel kalau dinasihati.)

(32) Mbok ra mbetu! (Jangan bandel!)

(33) Cah cilik nek dikandani mecicil wae. (anak kecil dinasihati bandel atau melotot terus.) 
Tambeng, mbetu, dan mecicil memiliki arti yang sama, yaitu bandel. Tuturan tersebut biasanya diucapkan orang tua saat menasihati anaknya atau saat senior menasihati juniornya.

(34) Mbokne wae lambe turah, pantes anake yo lambe turah.

(Ibunya saja tukang gosip, pantas anaknya juga tukang gosip.)

(35) Gakno ra sok nggambleh wae, tibo to.

(Makanya jangan suka nyinyir, jatuh kan.)

Lambe turah dan nggambleh sama-sama berkonotasi negatif. lambe turah berarti suka bergosip, nggambleh berarti suka nyinyir. Umpatan ini diucapkan seseorang karena merasa tidak suka dengan perilaku orang lain yang dirasakan negatif.

(36) Jidor ah.

(Biarin ah.)

(37) Dikandani malah do cengengesan!

Kata jidor diucapkan pada saat seseorang merasa kesal karena dinasihati, sedangkan kata cengengesan berarti tidak serius atau main-main.

(38) Mbok ojo ngglitis to yo

(Jangan usil donk!)

Ngglitis berarti usil. Tuturan ini biasanya ditujukan untuk anak kecil yang aktif, tidak bisa diam, dan sulit dinasehati sehingga membuat kesal.

3. Sarana untuk Mengungkapkan Rasa Kecewa,

Umpatan untuk menunjukkan rasa kecewa, seperti celes dan semangkean. Contoh tuturan:

(39) Celes, ket mambengi ra dibalesi Wane.

(sialan, dari semalam tidak dibalas WA-nya)

(40) Jaaaan..., dikongkon kok semangkean wae.

(Duuuuh... disuruh kok tidak serius terus.)

Pada tuturan tersebut, kata celes diucapkan sebagai bentuk kekecewaan karena pesannya tidak dibalas dari semalam. Celes berarti sialan. Kata semangkean 'tidak serius' juga diucapkan sebagai bentuk rasa kecewa.

4. Sarana untuk Mengungkapkan Rasa menyesal

(41) Asem, mending mau aku nggo honda dewe, ngenteni angkot suwi tenan.

(Sialan, mending dari tadi aku bawa motor sendiri, menunggu angkot lama sekali.)

Kata asem pada tuturan tersebut diucapkan pada saat penutur merasa menyesal karena tidak naik motor sendiri, menunggu angkot terlalu lama

5. Sarana untuk Mengungkapkan Rasa Heran,

Umpatan untuk menunjukkan rasa heran diantaranya, nguntal, gendeng, kenthir, koplak, edan

(42) Uwong kok isane nguntal wae, ra gelem kerjo.

(orang kok bisanya makan terus, tidak mau bekerja.)

Kata nguntal dalam tuturan tersebut muncul pada seseorang merasa heran dengan kebiasaan orang lain yang tidak bekerja, tetapi makan terus.

(43) Gendeng de'e ke, klambi suwek wae dinggo. 
(gila kamu, baju sobek dipakai.)

(44) Wong kenthir ndaan ya? (Orang gila apa ya?)

(45) Mbok ora koplak, hahaha...

(Jangan gila, hahaha...)

(46) Karang wong edan, senengane ngomong dewe.

(Namanya orang gila, suka berbicara sendiri.)

Kata gendeng, kenthir, koplak dan edan memiliki arti sama yaitu gila. Kata-kata tersebut muncul pada saat seseorang merasa heran terhadap orang lain karena berperilaku tidak wajar.

6. Sarana untuk menghina orang lain

Umpatan untuk menghina orang lain hanya ditemukan satu data, yaitu pada kata ciblek. Ciblek berari sejenis burung. Namun, ciblek memiliki makna konotasi negatis, yaitu perempuan murahan, atau panggilan.

(47) Dasar ciblek, yah mene gek wae bali.

(Dasar perenpuan bawaan, jam segini baru pulang.)

7. Menggambarkan Keakraban dalam Sebuah Hubungan

Umpatan untuk menunjukkan keakraban dalam sebuah hubungan, seperti

(48) Ket mau kok do ndopok wae to senengane.

(Dari tadi kok hanya bergosip saja.)

(49) Gundulmu, ngarang wae.

(Kepalamu, sembarangan saja.)

(50) Mbok ora umis wae.

(Jangan berbicara terus)

(51) Rasah bombongan, koyo ayu-ayuo wae.

(tidak usah GR (gede rasa), kayak cantik saja.)

(52) Alah, ngangkat ngono wae ra teyeng nduk.

(Alah, mengangkat begitu saja tidak kuat nduk.)

(53) Silit ah ngomong wae.

(Lubang pantat, berbicara terus.)

Kata ndopok, gundulmu, umis, bombongan, dan teyeng dalam tuturan tersebut berfungsi sebagai keakraban dalam sebuah hubungan. Artinya, kata-kata tersebut diucapkan pada orang-orang yang sudah dikenal dan tanpa tujuan untuk menyakiti, menghina, ataupun membuat kesal.

\section{Simpulan}

Berdasarkan hasil analisis variasi umpatan bahasa Jawa dialek Temanggung ditemukan beberapa jenis umpatan, diantaranya umpatan berdasarkan anggota tubuh 10, umpatan nama binatang (4, umpatan nama profesi bermakna negatif 1 , bagian pohon 1, umpatan tak ada referen 32 , kondisi intelegensia 2 , dan kesehatan mental 4. Jenis umpatan yang paling banyak adalah umpatan tak ada referen karena terkadang bentuk-bentuk umpatan tidak memiliki kata asal dan dibentuk secara konvensional pada tiap daerah. Dengan demikian, umpatan pada tiap daerah tentunya berbeda-beda sesuai dengan kesepakatan daerah tersebut.

Berdasarkan fungsinya, dalam penelitian ini ditemukan 7 fungsi, yaitu sarana untuk mengungkapkan rasa marah, kesal, kecewa, heran, menyesal, menghina dan keakraban. Dari beberapa fungsi tersebut, sarana untuk menyampaikan rasa kesal paling banyak ditemukan, selanjutnya adalah sarana untuk mengungkapkan rasa marah. Hal ini terjadi karena pada dasarnya, umpatan adalah kata-kata kotor dan tidak sopan sebagai bentuk ekspresi seseorang ketika marah dan kesal. 


\section{Ucapan Terima Kasih}

Penulis mengucapkan terima kasih kepada semua pihak yang terkait dalam penelitian ini, semoga penulisan ini dapat bermanfaat bagi ilmu pengetahuan, khususnya kajian kebahasaan dalam penggunaan kosakata dalam ujaran.

\section{Daftar Rujukan}

Djatmika. Mengenal Pragmatik Yux?. Yogyakarta, Pustaka Pelajar. 2016. http://eprints.uny.ac.id/19982/1/Budi\%20Sih\%20Yuliarini\%20102052440 11.pdf diunduh tanggal 10 Juni 2019.

Kamus Besar Bahasa Indonesia. [Daring]. kbbi.kemdikbud.go.id/entri/religius. Diunduh 10 Juni 2019.Moleong. Metodologi Penelitian Kualitatif. Bandung: Remaja Rosdakarya.Pustaka Pelajar.

Saptomo, S. W. Makian dalam Bahasa Jawa. Tesis. Yogyakarta, Program Pasca Sarjana Universitas Negeri Gajah Mada. 2001."

Wijana, I Dewa Putu. Sosiolinguistik: Kajian Teori dan Analisis. Yogyakarta. 2010.

Yuliarini, Budi Sih. Basa Pisuhan Dialek Banyumas Wonten Ing Lawakan Curanmor. 2014. 